Contents list available at IJRED website

Int. Journal of Renewable Energy Development (IJRED)

Journal homepage: http://ejournal.undip.ac.id/index.php/ijred

\title{
Application of Hydrothermal Treatment to High Concentrated Sewage Sludge for Anaerobic Digestion Process
}

\author{
M. Orikawa, H. Kamahara, Y. Atsuta, and H. Daimon* \\ Department of Environmental and Life Sciences, Toyohashi University of Technology, 1-1 Hibarigaoka, Tempaku-cho, \\ Toyohashi-shi, Aichi, 441-8580, JAPAN
}

\section{Article history:}

Received September 17, 2013 Received in revised form Oct. 23,2013 Accepted October 28, 2013 Available online

\begin{abstract}
Tomato and seaweed were produced by utilizing $\mathrm{CO}_{2}$ and heat discharged from power generation using biogas in Toyogawa biomass park, Japan. The biogas was obtained by anaerobic digestion with hydrothermal treatment. The hydrothermal treatment was applied to the high concentrated sewage sludge (22\% total solids (TS) dewatered sludge). The purpose of this study is to clarify the effect of hydrothermal treatment on the qualities of high concentrated sewage sludge, by analyzing particulate organic carbon (POC) and dissolved organic carbon (DOC). The hydrothermal treatment was investigated under $10-60$ min of treatment time, $180-200{ }^{\circ} \mathrm{C}$ of temperature, 10-22 \%-TS of sewage sludge concentration. The results showed that the DOC in each conditions increased through hydrothermal treatment. The highest DOC obtained was $67 \%$ of total carbon concentration, when the temperature was $180^{\circ} \mathrm{C}$, treatment time was 60 min and sewage sludge concentration was $10 \%$-TS. Furthermore, the viscosity of treated sewage sludge was decreased by hydrothermal treatment. In batch anaerobic digestion test, methane gas production was confirmed. In addition, this study evaluated the energy balance of this system. Thus, the results of this study indicated that the possibility of application of hydrothermal treatment to high concentrated sewage sludge for anaerobic digestion process.
\end{abstract}

Keywords: anaerobic reaction, hydrothermal treatment, sewage sludge, solubilization

\section{Introduction}

Anaerobic digestion is effective in the biogas recovery and the volume reduction of sewage sludge which was accounted for the highest percentage in the industrial waste (Ministry of the Environment 2012). Especially, hydrothermal treatment was added as a pretreatment technology for anaerobic digestion process that attracted many attentions. The digestion of sewage sludge is promoted by hydrolysis of hydrothermal treatment and the amount of biogas produced is increased (Ohmura et al. 2004). Futhermore, the viscosity is reduced by causing the release of water sewage sludge had been held (Hujimoto et al. 2006). Thus, even a high concentrated sewage sludge that has high viscosity can be stirred in digestive tank and dumped as a raw material. The usage of low water content of high density sewage sludge as a raw material is expected to reduce the energy consumption of the hydrothermal treatment. The best hydrothermal treatment is resulted in temperature of 120-180 ${ }^{\circ} \mathrm{C}$ and times 30-60 min for activated sludge (TS of 96-99\%) (Tania et al. 2013). Bougrier et al. (Tania et al. 2013) clarified that hydrothermal treatments at temperatures of $70{ }^{\circ} \mathrm{C}$ or $121^{\circ} \mathrm{C}$ which led to a $20-30 \%$ biogas production increase and treatments at $160-180{ }^{\circ} \mathrm{C}$ which led to a $40-100 \%$ biogas production increase. Wei et al. (2011) examined biogas production from supernatant of hydrothermally treated municipal sludge. Research on physical properties such as viscosity and dewatering of sludge by hydrothermal treatment have been made (Claire et al. 2008) and (Kobayashi et al. 2011). In addition, anaerobic digestion process which incorporates a hydrothermal treatment with sewage sludge, has been operated as a commercial plant (Mitsubishi Nagasaki Mashinery MFG. CO., LTD

\footnotetext{
* Corresponding author:

E-mail: daimon@ens.tut.ac.jp
} 
2012). However, study on the sludge concentration has not been studied so far. In this study, the target is high concentrated sewage sludge $(10 \%$-TS over sludge concentration), which achieved by using hydrothermal treatment that examined the low viscosity and molecular weight of organic matter. Additionally, anaerobic digestion test was performed to examine the effect of hydrothermal treatement. Finally, this study shows the relationship between TS of sewage sludge and the net energy production of the hydrothermal treatment on $180{ }^{\circ} \mathrm{C}$.

\section{Experiments}

\subsection{Solubilization test of organic matter by hydrothermal treatment}

The sample used was dehydrated sludge (sludge were mixed after the final sedimentation tank sludge and primary sedimentation tank sludge, and dried 22 $\%$-TS concentration) which were collected from Toyogawa wastewater treatment center. After adjusting the concentration up to $10 \%$ and $15 \%$, the dehydrated sludge was used in hydrothermal treatment under conditions treatment temperature $180,200{ }^{\circ} \mathrm{C}$, treatment time 10, 30, 60 min.

Total carbon (TC) was measured using the elemental analyzer (Elementar, varioEL III). In this study, dissolved organic carbon (DOC) was defined by filtering through a membrane filter (ADVANTEC, pore size $0.45 \mu \mathrm{m}$ ) where samples were diluted 1000 times. POC was obtained by subtracting the DOC from TC. DOC were measured using the organic carbon concentration meter (Shimadzu, TOC-L). The DOC was used as an index for low molecular weight and solubilization of organic matter.

\subsection{Viscosity test}

The viscosity of hydrothermal treated sludge samples and the untreated sludge samples were measured by using the viscometer (viscometer Toki Sangyo, TCV-7). The conditions of hydrothermal treatment were 15, $22 \%$ sludge concentration, 180, $200{ }^{\circ} \mathrm{C}$ treatment temperature and 10, $60 \mathrm{~min}$ treatment time.

\subsection{Batch anaerobic digestion test}

Batch anaerobic digestion test was performed in a medium bottle of volume $1 \mathrm{~L}$, with a ratio of $3: 1$ substrate sludge and seed sludge, within the culture shaker (TAITEC, Bio-shaker). Digestion trial of 10 days was maintained at $55{ }^{\circ} \mathrm{C}$. The conditions of hydrothermal treatment were $15 \%$ sludge concentration, $180,200{ }^{\circ} \mathrm{C}$ treatment temperature and 60 min treatment time. After hydrothermal treatment for $15 \%$-TS sewage sludge, all of the substrate sludge was adjusted to $87.4 \%$ moisture content and same $\mathrm{pH}$.
For anaerobic seed sludge, three kinds of anaerobic digestion solution which were able to confirm the production of gas were used as a substrate sewage sludge. Two of the seed sludges were thermophilic digestion solution and the other one is mesophilic digestion solution. In the medium bottle, the sampling tube and gas recovery pack were connected and the digestive solution in $8 \mathrm{~mL}$ per days was collected, followed by measurement of DOC and $\mathrm{pH}$. The recovered gas pack after 10 days were analyzed for gas composition using gas chromatograph (Shimadzu, GC8A). In addition, Volatile Solids (VS) of digestive solution was measured in accordance with sewer test method.

\subsection{Energy balance of the system}

Energy consumption is required for hydrothermal treatment to improve the characteristic of the sewage sludge for anaerobic digestion. Therefore, an evaluation of energy balance is required to obtain the net energy from sewage sludge. Energy consumption of hydrothermal treatment will be reduced due to decrement of the water content of sewage sludge. On the other hand, biogas production will be increased due to decrement of the water content of sewage sludge. This study evaluated this balance. Table 1 showed the assumptions for the evaluation of energy balance. The temperature of sewage sludge and hydrothermal treatment was assumed $20^{\circ} \mathrm{C}$ and $180{ }^{\circ} \mathrm{C}$ respectively.

Table 1.

Assumption for evaluation of energy balance

\begin{tabular}{lc}
\hline Carbon content of sewage sludge & $39.2 \%-\mathrm{DS}$ \\
Biogas production ratio & $60 \%-\mathrm{C}$ \\
Methane content & $60 \%-\mathrm{C}$ \\
LHV of methane & $50 \mathrm{MJ} / \mathrm{kg}$ \\
Efficiency of boiler & $90 \%$ \\
\hline
\end{tabular}

\section{Results and Discussion}

\subsection{Solubilization test of organic matter by hydrothermal treatment}

The ratio of DOC in each sample sludge concentration by hydrothermal treatment $180{ }^{\circ} \mathrm{C}$ and $200{ }^{\circ} \mathrm{C}$ treatment temperature was shown in Fig. 1. The ratio of DOC was increased in all concentration after hydrothermal treatment. However, a significant increase in DOC was not shown by the treatment time. Therefore, organic matters which was easily decomposed was solubilized in a short time, but other organic matters which was not easily decomposed after treatment time, was confirmed. Furthermore, the ratio of DOC was higher when the sludge concentration was low. Thus, as the water content was large, solubilization was likely to be promoted. Comparing the results of 200 ${ }^{\circ} \mathrm{C}$ and $180{ }^{\circ} \mathrm{C}$ reaction temperature, ratio of DOC was same level. Fig. 1 showed that there is no significant 
difference in the solubilization ability of the hydrothermal reaction due to temperature difference treatment.

\subsection{Effect for viscosity of high concentrated sludge by hydrothermal treatment}

The viscosity of samples before and after hydrothermal treatment in each condition was shown in Table 2. Except of the $22 \%$-TS sludge concentration ( $180{ }^{\circ} \mathrm{C}$ treatment temperature, 10 min treatment time), every sample's viscosity was below than $10 \mathrm{~Pa} \cdot \mathrm{s}$. These are the characteristic which allow pumping the sludge smoothly. Therefore, it can be applied to a hydrothermal treatment, where handling (stirring and sludge transport) is possible even in a high concentrated sludge in the anaerobic digestion process had been clarified.

\subsection{Batch anaerobic digestion test}

A transition POC concentration, DOC concentration and $\mathrm{pH}$ of digestive solution in batch anaerobic digestion tests using untreated sludge and hydrothermal treatment sludge of $200{ }^{\circ} \mathrm{C}$ temperature were shown in each Fig. 2. Total organic carbon

(a)

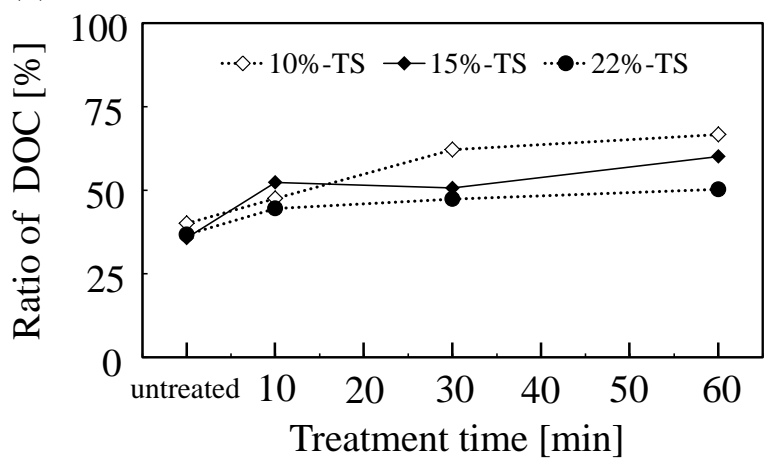

concentration was decreased by time, in particular POC concentration. Similiar results was obtained for $180{ }^{\circ} \mathrm{C}$ treatment temperature. However, the reduction of the organic matter concentration was small due to the not smoothly done organic decomposition.

VS degradation rate of digestion solution and the methane concentration were shown in Table 3. The highest VS degradation rate was $46 \%$ of digestion solution with hydrothermal untreated sludge. However, since methane gas was not detected, methane fermentation might have not been fully performed. On the other hand, in the anaerobic digestion test of hydrothermal treatment of sludge treatment temperature $200{ }^{\circ} \mathrm{C}$, methane gas concentration was the highest with $49 \%$. Consequently, digestion speed was accelerated by hydrothermal treatment and methane was generated until a short period of time.

\subsection{Energy balance}

Fig. 3 shows the energy balance as the relationship between total solids of sewage sludge and net energy production. From this result, net energy gain was obtained over $7.4 \%$-TS under $180{ }^{\circ} \mathrm{C}$ of reaction time. This point will be increased to $8.3 \%$ under $200{ }^{\circ} \mathrm{C}$ of reaction time. Therefore, net energy gain can be obtained by this system.

(b)

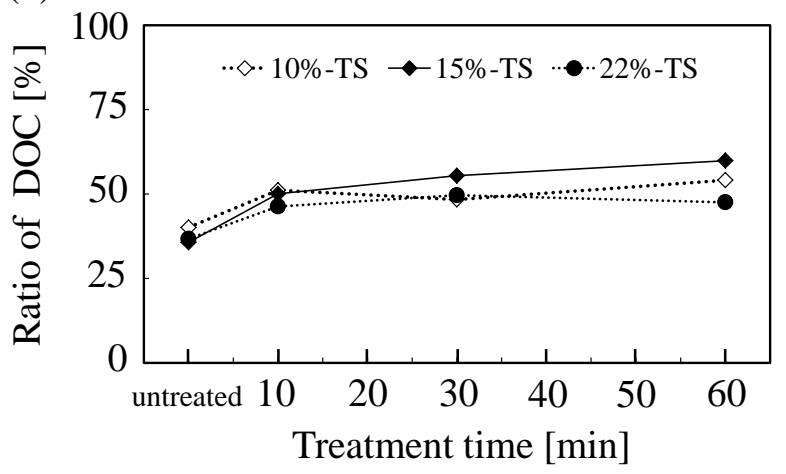

Fig. 1 The ratio of the DOC of each sludge concentration by hydrothermal treatment at (a) $180{ }^{\circ} \mathrm{C}$ and (b) $200{ }^{\circ} \mathrm{C}$.

(a)

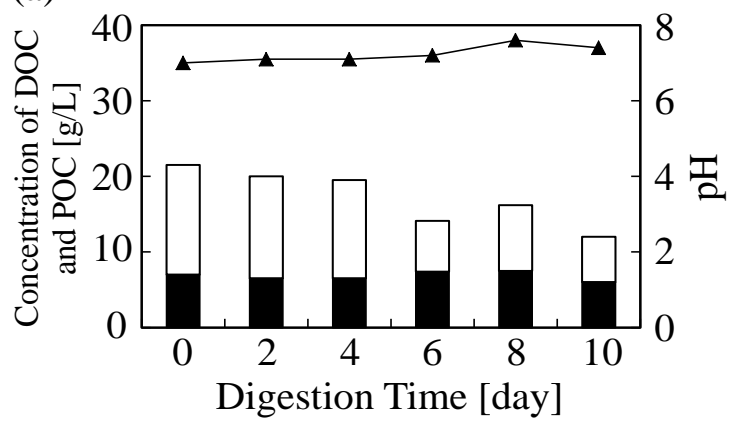

(b)

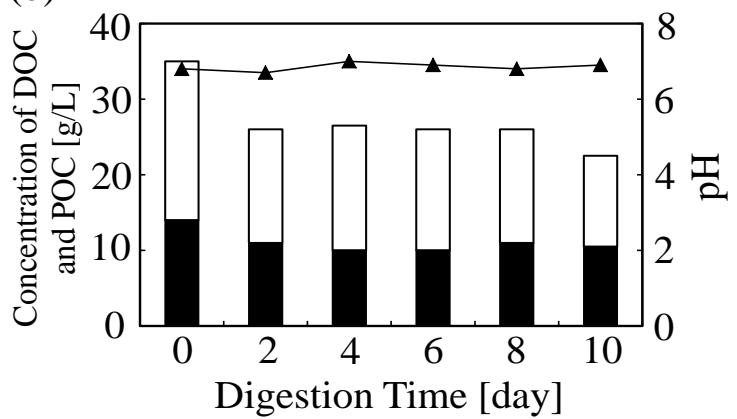

: POC

$: \mathrm{DOC} \iota: \mathrm{pH}$

Fig. 2 POC, DOC and the pH of the anaerobic digestion solution using hydrothermal treatment for (a) $15 \%$-TS untreated sludge and (b) $15 \%$-TS treated sludge (Treatment temperature : $200^{\circ} \mathrm{C}$ and treatment time : $60 \mathrm{~min}$ ) 


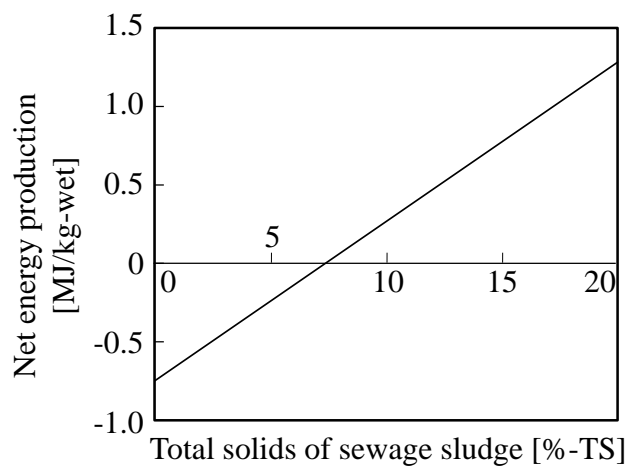

Fig. 3 The energy balance as the relationship between total solids of sewage sludge and net enrgy production.

Table 2.

Viscosity of the sewage sludge obtained under each hydrothermal treatment conditions

\begin{tabular}{cccccc} 
& Sludge concentration & \multirow{2}{*}{ untreated } & $\begin{array}{c}\mathbf{1 8 0}{ }^{\circ} \mathbf{C}, \\
\mathbf{1 0} \text { min }\end{array}$ & $\begin{array}{c}\mathbf{1 8 0}^{\circ} \mathbf{C}, \\
\mathbf{6 0}_{\mathbf{m i n}}\end{array}$ & $\begin{array}{c}\mathbf{2 0 0}^{\circ} \mathbf{C}, \\
\mathbf{6 0} \text { min }\end{array}$ \\
\hline Viscosity & $15 \%$-TS & 49.5 & 2.7 & 1.6 & 0.3 \\
{$[\mathrm{~Pa} \cdot \mathbf{s}]$} & $22 \%$-TS & N.D & 12.8 & 5.8 & 3.8 \\
\hline
\end{tabular}

Table 3.

Volatile Solids (VS) degradation rate and methane concentration in biogas collected

\begin{tabular}{lcc}
\hline \multicolumn{1}{c}{ Substrate sludge } & VS degradation rate[\%] & Methane gas concentration [\%] \\
\hline Untreated sludge & 46 & N.D \\
Hydrothermal treated sludge $\left(180^{\circ} \mathrm{C}, 60 \mathrm{~min}\right)$ & 25 & N.D \\
Hydrothermal treated sludge $\left(200^{\circ} \mathrm{C}, 60 \mathrm{~min}\right)$ & 31 & 49 \\
\hline
\end{tabular}

\section{Conclusions}

Solubilization of high concentrated sludge was promoted by hydrothermal treatment. Between sludge concentration $10 \%$ and $22 \%$, DOC concentration was increased as the lower sludge concentration. However, a significant difference in the treatment range of 180-200 ${ }^{\circ} \mathrm{C}$ treatment temperature and 10-60 min treatment time was not observed. Furthermore, the low viscosity of the sludge could be shown by the hydrothermal treatment, it was reduced to about handling at the pump general is possible. It was considered that anaerobic digestion test with hydrothermal treated sludge, decrement volatile solids was low, but was led to methane production. However, decrease in the amount of organic matter overall was low, gas generation amount was small. In the evaluation of the energy balance, it was estimated the net energy gain can be obtained in more than 7-8 \% sludge concentration. Thus, the possibility of application to anaerobic digestion of high concentrated sludge become clear. Future continuous testing of anaerobic digestion is required.

\section{Acknowledgement}

Toyogawa wastewater treatment center owned by Aichi prefecture helped us to conduct this work. This work is supported by Funds for integrated promotion of social system reform and research and development, MEXT, Japan.

\section{References}

Ministry of the Environment.. Report of present Industrial waste treatment 2011. URL http://www.env.go.jp/recycle/ waste/sangyo/sangyo_h-21a.pdf. Accessed on 16 December 2012

Ohmura, T., Ukai, N., Horizoe, K., Sato, J., Ueda, R. \& Horizoe, H. (2004) A Study on Hydrothemal Enhancement of Sewage Sludge Anaerobic Digestion. Mitsubishi Heavy Industries Technical Review, 41, 220-223.

Hujimoto, S., Yanagida, T., Sakanishi, K., \& Minowa, T. (2006) Powderization of sewage sludge by hydrothermal treatment. In Twelfth Fluidization and Particle Processing Symposiumu, 265269. Tsukuba center, Ibaraki, Japan. : Fluidization and Particle Processing Symposium.

Tania, F.C., Ricardo, I., Montserrat, P., Clarita, S., in Ackmez, M. ed. (2013) Biogas Production-Pretreatment Methods in Anaerobic Digestion. Wiley-Scrivener.

Wei, Q., Chong, P., Wei, W., ZhongZhi, Z. (2011) Biogas production from supernatant of hydrothermally treated municipal sludge by upflow anaerobic sludge blanket reactor. Bioresource Technology, 102, 9904-9911.

Claire, B., Jean, P.D., Helene, C. (2008) Effets of thermal treatments on five different waste activated sludge samples solubilisation, physical properties and anaerobic digestion. Chemical Engineering Journal, 139, 236-244.

Kobayashi, S., Nomura, S., Hujimura, Y., Tsuboi, H., Kimoto, K., Itaya, Y. (2011) Effects of hydrothermal treatment on sewage sludge treatment residues characteristics. Kagaku Kogaku Ronbunsyu, 37, 460-467.

Mitsubishi Nagasaki Mashinery MFG. CO., LTD. (October 2012). URL http://www.mnm.co.jp/product/kankyo/sewage-grime.html. Accessed on 12 December 2012. 